\title{
Da doutrina do interesse bem compreendido n'A Democracia na América ${ }^{1}$
}

\section{The Doctrine of Interest Properly Understood in Democracy in America}

\author{
Roberta K. Soromenho Nicolete ${ }^{2}$ \\ Universidade de São Paulo (Brasil)
}

Recibido: 06-08-18

Aprobado: 10-05-19

\section{Resumo}

Frágil é, segundo Alexis de Tocqueville, o equilíbrio em que se encontra a liberdade em um estado social de igualdade de condições. Tomados pela sua maior paixão, a da igualdade, os homens democráticos podem assistir a conversão da liberdade em despotismo ao se entregarem à busca exclusiva de seus interesses e bens privados, ao abdicarem da faculdade de julgar, deixandose guiar servilmente pela opinião da maioria, a fonte da autoridade em tal estado social. Em face disso, este artigo sustenta que, ao discorrer acerca dos costumes estadunidenses, n’A Democracia na América, o autor não faz mera descrição mas delineia uma teoria social, a doutrina do interesse bem compreendido, a qual relacionaria, na república americana, a virtude e o interesse, e poderia fornecer elementos para instruir as sociedades democráticas.

Palavras-chave: liberdade, virtude, interesse, interesse bem compreendido, A Democracia na América, Tocqueville.

\footnotetext{
${ }^{1}$ Agradeço aos professores Eunice Ostrensky e Marcelo Jasmin pelas leituras e a Antonio Hermosa, Maria Luisa Rodriguez e Nere Basabe pela generosidade. O presente artigo consiste em versão expandida de uma comunicação sobre o mesmo tema apresentada no IV Seminário Discente da Ciência Política da USP, em 2014. Trata-se ainda de versão modificada do Capítulo 2, do livro Quando a política caminha na escuridão - Interesse e virtude n'A Democracia na América de Tocqueville, (Nicolete 2018: 69-119). Este trabalho foi apoiado pela Fundação de Amparo à Pesquisa do Estado de São Paulo (FAPESP processo 2010/02307-8).

2 (robertasoromenhonicolete@gmail.com) Pós-doutoranda no Departamento de Filosofia da Universidade de São Paulo (USP-Brasil). Doutora (2017) pelo Programa de Pós-Graduação em Ciência Política (USP) e pela École des Hautes Études en Sciences Sociales (EHESS-França). Mestra (2013) em Ciência Política (USP). Autora de Quando a política caminha na escuridão - Interesse e virtude n'A Democracia na América de Tocqueville. São Paulo: Ed. Alameda, 2018 e de "Catecismo do cidadão - constitucionalismo e soberania popular em Guillaume de Saige". Revista Brasileira de Ciências Sociais - RBCS (101) 2019, no prelo.
} 


\begin{abstract}
According to Alexis de Tocqueville, in the state of equality of conditions liberty is under serious threat. The passion for equality, which is the first and most intense passion of a democratic people, may prompt them to exchange liberty for despotism, in so far as they are willing to surrender themselves entirely to the search of material goods and self-interest, and to resign their power of judgment for the sake of the opinion of the majority, which is the real source of authority in such a social state. Taking this fragile balance between liberty and equality into account, this paper aims the consideration of American customs which allows Tocqueville to postulate a social theory (not a description of this society), the doctrine of interest properly understood, which may link analytically virtue and interest and instruct democratic societies.
\end{abstract}

Key-words: Liberty, Virtue, Interest, interest properly understood, Democracy in America, Tocqueville.

Para o professor Sérgio Cardoso

\title{
Introdução
}

"O interesse, aí está o segredo [...] $\mathrm{O}$ interesse que no mais se produz ostensivamente e se anuncia como uma teoria social $[\ldots]$

E a República é para isso o melhor dos governos".

(Carta de Tocqueville a Chabrol) ${ }^{3}$

Em uma carta enviada a Ernst Chabrol, em 9 de Junho de 1831, Alexis de Tocqueville indaga mediante qual artifício se relacionariam homens tão diferentes entre si e ciosos dos seus interesses quanto os estadunidenses observados em sua viagem à América. Na pena tocquevilleana, a proposição que serve de resposta à especulação clássica acerca do fundamento moral para a ação política entre os homens mobiliza a linguagem política dos interesses e da virtude ${ }^{4}$.

\footnotetext{
${ }^{3}$ No original: "Qui sert de lien à des éléments si divers? Qui fait de tout cela un peuple? L'intérêt, c'est là le secret [...]". A tradução é de responsabilidade da autora, quando as edições não estiverem mencionadas.

${ }^{4}$ Nesse aspecto, estamos de acordo com Lucien Jaume, a quem Tocqueville era herdeiro do grupo de Coppet, em especial, Benjamin Constant, ao privilegiar os interesses e o jogo constitucional, em oposição aos liberais doutrinários, mais bem representados na figura de François Guizot, seu professor. Embora não esteja no escopo deste artigo comparar Tocqueville com Constant ou com os doutrinários, pois há ampla bibliografia sobre isso, é preciso mencionar que o debate sobre o lugar 
A afirmação do autor ("o interesse, aí está o segredo) sugere que o interesse não apenas responderia pela associação entre os homens em uma sociedade democrática, cuja característica principal é o individualismo e o sentimento de apequenamento em meio a multidão (Tocqueville 2004: 138; TII, P2, c6) 5 , mas que o interesse se anunciaria "como uma teoria social". Com efeito, o autor admite o interesse como elemento constitutivo das repúblicas modernas sem vinculá-lo, de imediato, à sua corrupção ${ }^{6}$. De anotações esparsas e impressões partilhadas em suas correspondências, o tema do interesse reaparece em dois capítulos da obra mais conhecida do autor, A Democracia na América [1835-1840].

Acostumados com o juízo elogioso que Tocqueville endereça aos homens da Nova Inglaterra, tomados por intenso desejo material, dados à inveja e ao egoísmo, no mesmo instante em que zelam pelo interesse comum, causa inquietação aos leitores a seguinte formulação, a certa altura d'A Democracia: "essa gente crê seguir a doutrina do interesse, mas só tem dela uma ideia grosseira e, para zelar melhor pelo que chamam seus negócios, negligenciam o principal, que é permanecer donos de si mesmos" (Tocqueville 2004: 172; TII, P2, c14).

A "gente", a qual o francês se refere no excerto, seguiria certa doutrina do interesse, não fosse ela desconsiderada pelo autor como mera ideia grosseira e deturpada. Deturpada, pois remete à busca de bem-estar e segurança material sem atentar para o "domínio de si" . Ora, estaríamos diante de um impasse na interpretação do capítulo 14 d'A Democracia ("Como, nos americanos, o gosto pelas fruições materiais se une ao amor à liberdade e à preocupação com os negócios públicos"): tudo leva a crer que a "gente" referida no excerto seria o povo estadunidense. Entretanto, como a argumentação na sequência dos capítulos que tratam da doutrina do interesse e do individualismo nas sociedades democráticas indica, a paixão pelo bem-estar não privava os americanos da liberdade, porque, entre eles, o interesse era bem compreendido (bien entendu). É possível sair desse impasse na interpretação, se notarmos

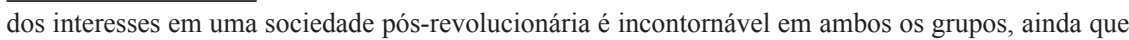
as consequências e apostas políticas sejam inteiramente distintas. Ver: Jaume 1997 e Meuwly 2002.

5 Para facilitar a localização das citações, visto que são diversas as edições da obra disponíveis, todas as citações da A Democracia na América são especificadas por tomo (T), parte $(\mathrm{P})$ e capítulo (c).

${ }^{6}$ Lembremos que, para Montesquieu, a virtude é o princípio das Repúblicas (Montesquieu LIII cap. 3).

7 Outras passagens d'A Democracia (2004) poderiam sustentar a centralidade que a ideia de independência, como domínio de si, possui na composição da noção de liberdade tocquevilleana: "[...] é difícil para o cidadão receber de fora sua regra. Esse gosto e esse uso da independência o seguem nos conselhos nacionais [...]" (Tocqueville 2004: 105; TII, P1, c21). A nossa interpretação é corroborada por Jean-Fabien Spitz, segundo o qual “(...) nesse sentido, ele [Tocqueville] é atado à manutenção da ideia de que a independência em relação à dominação é o núcleo do conceito de liberdade" (Spitz 1995: 484), e Reis: "a ideia tocquevilleana de liberdade supõe a independência individual, em primeiro lugar" (Reis 2010: 84). Jasmin também destaca a autodeterminação como o sentido intrínseco da noção de liberdade (Jasmin 2005: 239). 
que o autor opera um deslocamento do ponto observado, a América, e amplia o alcance de suas análises. Tal ampliação seria marcada por evidente ruptura, por brusca generalização, na seguinte sentença, a qual inicia um novo momento na argumentação do capítulo: "De fato, há uma passagem perigosíssima na vida dos povos democráticos" (Tocqueville 2004: 172 grifos nossos).

A interpretação sustentada neste artigo é a de que este novo momento na argumentação do autor é aquele no qual o francês aborda as implicações das fruições materiais e dos interesses para a vida política dos "povos democráticos" em geral - e não apenas da sociedade estadunidense. Argumentamos que parte da estratégia retórica de Tocqueville consistia em instruir as sociedades democráticas - em particular, a França - recorrendo às suas análises nas terras do outro lado do Atlântico. Fundem-se, nesse momento da obra, aspectos descritivos e prescritivos para a democracia. Ao discutir a doutrina do interesse bem compreendido, entre outras acepções do termo interesse, o autor torna não apenas indissociáveis mas complementares o interesse e o novo estado social de igualdade de condições. Por essa razão, sustentamos que o deslocamento da descrição de um caso particular, a sociedade estadunidense, para as democracias entendidas de modo mais geral e abstrato (Benoît 2013: 337) é um movimento retórico que permitiu a Tocqueville vincular uma doutrina moral elevada e amparada na renúncia de si às sociedades aristocráticas e, com isso, abrir a sua investigação sobre a virtude possível nas repúblicas modernas, afastandose ao mesmo tempo do utilitarismo anglo-saxão e da virtude na acepção de Montesquieu (Schleifer 2000: 294).

Com efeito, o argumento desenvolvido neste artigo compreende um esforço, na primeira seção, de recusa de sentidos usuais do termo "interesse", mediante o qual inserimos Tocqueville em um debate mais amplo acerca de doutrinas morais do interesse, a partir das três acepções do termo por ele mesmo esboçadas nas notas de preparação para $A$ Democracia. Indicadas as objeções de Tocqueville a tais doutrinas, o emprego da expressão adjetiva "bem compreendido" parecerá menos fortuito bem como o sentido usual da palavra interesse, na acepção de "espera de vantagens ou de ganhos", será afastado. $\mathrm{Na}$ segunda seção, nos debruçamos sobre a doutrina do interesse bem compreendido (l'intérêt bien entendu), enfatizando nela certa relação entre a virtude e o interesse. Esses termos são contrastantes em muitas obras do pensamento político, razão pela qual examinamos duas interpretações opostas, a de Martin Zetterbaum e Roger Boesche, os quais reiteram a leitura da doutrina em chave excessivamente polarizada entre o interesse ou a virtude. Argumentamos que, na pena de Tocqueville, a virtude do homem democrático se calca sobre o seu interesse (Meuwly 2002: 208). Mais do que isso, as linguagens da virtude e do interesse estão articuladas na doutrina do interesse bem compreendido. A esse respeito, não cabe recorrer apenas à obra publicada mas é decisivo o estudo 
das notas de preparação, nas quais o autor afirma "precisar da América" para provar que "nas épocas democráticas, a virtude e o interesse estão em acordo" (Tocqueville 2010: 920 nota g).

O fato de se dirigir a uma sociedade democrática é condição necessária do estabelecimento dessa doutrina, a qual se aparta do esquecimento de si, virtude aristocrática, e adquire traços de utilidade. Aproximado, no mais das vezes, do utilitarismo de Bentham ou do liberalismo de Constant, Tocqueville raramente foi interpretado mediante a menção que ele faz de passagem a Montaigne em rara apresentação das suas fontes. A sequência do artigo segue a senda da ironia contida na referência ao autor dos Ensaios, indicando como Tocqueville se aproxima e se afasta da ideologia francesa da vontade geral. A interpretação sustentada, nesta seção do artigo, é a de que a acepção de virtude contida na doutrina do interesse bem compreendido é o elemento fundamental da alteração de sentido pretendida nas linguagens da virtude e do interesse, permitindonos, a nós, leitores contemporâneos, tomá-la não apenas como uma categoria tocquevilleana descritiva, mas como uma teoria social com elementos, em parte, normativos para as sociedades democráticas.

\section{Doutrinas do Interesse}

Na economia textual d'A Democracia na América, a compreensão da noção de interesse e, especificamente, do conceito "interesse bem compreendido" ("l'intérêt bien entendu") apenas se completa quando percorremos toda a Parte II, do Tomo II [1840], bem como as notas de preparação da obra, pois a exposição da doutrina origina-se na discussão acerca do individualismo nas sociedades democráticas. Os comentadores da obra, de modo geral, se concentram sobre a caracterização do individualismo nas sociedades de igualdade de condições e, por ser tratada diretamente em apenas dois capítulos, a doutrina do interesse bem compreendido é tida por tema secundário no argumento geral da obra ${ }^{8}$. Entretanto, um percurso mais amplo nos permite recolher diversos elementos evidenciando a inserção do interesse bem compreendido em uma discussão mais geral acerca de doutrinas morais. Isso porque, uma das prioridades entre os contemporâneos a Tocqueville, entre finais do século XVIII e início do XIX, era justamente a de pensar o modo pelo qual deveriam ser relacionados os indivíduos em uma sociedade que não mais conhecia laços fixos e imutáveis

\footnotetext{
${ }^{8}$ Ainda que apenas em dois capítulos a doutrina do interesse seja abordada, não se trata de um tema menor - e é isso que justifica sua centralidade neste artigo. Analisá-la pode nos levar a compreender o fundamento moral da ação política dos homens no estado social que substitui a ordem aristocrática. Para Pierre Manent, aliás, o fato de dois capítulos d'A Democracia apresentarem como tema central justamente a doutrina sinalizaria a importância do objeto no argumento do autor (Manent 1993: 167). A esse respeito ver também: Meuwly 2002: 207-210.
} 
de pertencimento e que tampouco oferecia um fundamento incontestável para a composição da autoridade política.

$\mathrm{O}$ abismo era a imagem amplamente empregada no período e fazia referência não apenas à fúria dos eventos revolucionários, mas à desconcertante passagem do Antigo regime para o novo estado social igualitário. Desse modo, a ideia de que os interesses dos indivíduos estreitariam todos no puro egoísmo e tornaria os homens indiferentes aos demais, produzindo uma ordem política marcada pelos interesses individuais, parecia ser disseminada em distintos discursos políticos. Porém, o idealismo de uma vida virtuosa não havia sido completamente suprimido, de modo que o complexo diálogo entre os interesses e as virtudes perdurou neste período (cf. Armitage 2009: 10). Tocqueville busca tornar tal relação indissociável no interior da sociedade democrática, atribuindo certo sentido a um termo polissêmico e disputado no período: o interesse ${ }^{9}$.

O indício mais contundente de que, ao analisar a doutrina do interesse, Tocqueville mirava, em parte, a composição de um debate sobre doutrinas morais é textual e se encontra em um fragmento dos rascunhos d' $A$ Democracia ${ }^{10}$. Nesse fragmento, Tocqueville explicita que o objetivo do capítulo era "estabelecer distinções entre as diferentes doutrinas do interesse" (Tocqueville 2010: 923, nota n). A partir disso, o autor esboça três doutrinas que, em comparação, oferecem o sentido de uma quarta, a doutrina do interesse bem compreendido. O nosso objetivo nesta seção é expor tal esboço, inserindo os comentários de Tocqueville em um debate mais geral sobre doutrinas do interesse.

9 "La doctrine de l'intérêt bien entendu - qui correspond, par nature, le plus exactement possible à la démocratie - est une reprise des idées des Lumières par le pragmatisme des Américains. Les grands hommes de la révolution américaine [...] ont mis en évidence l'idée que le bien commun et le bien individuel sont complémentaires et non pas antagonistes" (Benoît 2013: 345).

${ }^{10}$ Cabe ressaltar que Adam Smith, em Teoria dos Sentimentos Morais (Parte 7, Seção 2), ao sistematizar diferentes naturezas da virtude, as reduz a três classes (a benevolência, a prudência e a conveniência), dividindo os afetos humanos em "egoístas" ou "benevolentes". Não temos provas materiais, nem mesmo nos rascunhos d'A Democracia, que nos permita inferir que Tocqueville quem raramente revela suas fontes - estivesse em diálogo com o escocês ao esboçar as doutrinas do interesse, embora conhecesse a obra de Smith. Pode ser afirmado, porém, que ele remete - e mesmo parafraseia - a Smith na análise desenvolvida no capítulo XX (TII, PII) "Como a aristocracia poderia originar-se da indústria" (cf. Drescher 1994: 60-61). Todavia, é possível afirmar que o autor d'A Democracia não está ocupado com a justificação da origem dos desejos e afetos, pois para Tocqueville o amor ao bem-estar e a predisposição ao útil não aparta os homens da busca por alguma espécie de virtude própria às sociedades democráticas. A crítica de Smith endereçada a Hutcheson, na Teoria dos Sentimentos Morais, segundo a qual o autor não havia alçado o interesse a um patamar elevado em sua teoria e tampouco considerado que o amor-próprio poderia estar na origem de ações virtuosas poderia estar na pena de Tocqueville. Entretanto, a crença no benefício econômico do "self-interest" que permeia toda a A Riqueza das Nações ("We address ourselves, not to their humanity but to their self-love, and never talk to them of our own necessities but of their advantages. Nobody but a beggar chuses to depend chiefly upon the benevolence of his fellow-citizens" LI, cap. 2, "Do princípio que origina a Divisão do Trabalho") e oferece o solo da ciência econômica não pode ser transferida para a A democracia apenas porque Tocqueville coloca no centro de sua análise o conceito de "interesse".

Sobre os rascunhos d'A Democracia cabe destacar o trabalho de Marcelo Jasmin (Jasmin 2000: 71-87).

Araucaria. Revista Iberoamericana de Filosofía, Política, Humanidades y Relaciones Internacionales, año $21, \mathrm{n}^{\circ} 42$. Segundo semestre de 2019. Pp. 449-474. ISSN 1575-6823 e-ISSN 2340-2199 doi: 10.12795/araucaria.2019.i42.19 
A primeira das doutrinas exposta pelo francês consistira na ideia de que é razoável supor que os interesses dos outros devem ser rebaixados diante dos interesses que concernem exclusivamente a si. Trata-se, nas palavras do autor, de rude egoísmo ou de um egoísmo instintivo, razão pela qual apenas com muita concessão mereceria o nome de doutrina ${ }^{11}$. A esse comportamento de egoísmo grosseiro, Tocqueville confrontará o "egoísmo esclarecido", ao discutir a doutrina do interesse bem compreendido.

Após a indicação dessa doutrina fundamentalmente egoísta, haveria também a da utilidade, com a qual, insiste Tocqueville, a doutrina do interesse bem compreendido "não deveria ser confundida", pois, ainda que nesta esteja contido certo traço de utilidade, não se trata de uma doutrina cujo fundamento último seja a utilidade ${ }^{12}$. Estamos de acordo com o estudioso Lucien Jaume, para quem a utilidade, nesse caso, não passa de um valor secundário ${ }^{13}$. Além destas notas do autor, publicadas na edição crítica da obra, outra evidência textual de que Tocqueville pretendia se afastar da moral utilitária pode ser encontrada na "Introdução" d'A Democracia. Parece-nos razoável interpretar que contra os utilitaristas, "paladinos da civilização moderna", como Tocqueville a eles se reporta, ele afirma: “em nome do progresso, esforçando-se por materializar o homem, querem encontrar o útil sem se preocupar com o justo, a ciência longe das crenças e o bem-estar separado da virtude" (Tocqueville 2001: 18; TI, Introdução, grifos nossos). A objeção às doutrinas morais apresentadas por Tocqueville permite sustentar que o adjetivo "bem compreendido" (bien entendu) empregado à doutrina não é fortuito e revelaria uma norma moral justa amparada nas crenças e nos costumes e na qual a garantia do bem-estar não se apartaria da virtude.

Por fim, está a doutrina mais pura e elevada fundamentada no dever. Tratase, nas palavras do autor, de um ato mediante o qual o homem penetra no pensamento divino, de modo que ele percebe que o objetivo de Deus é a ordem e se associa livremente ao Seu desígnio ${ }^{14}$. Para o nosso argumento, é importante ressaltar que um traço característico dessa doutrina essencial ou imaterial é a insistência na necessidade de extirpar as paixões. Um controle do homem sobre algo que lhe escapa, os seus desejos, em nome de uma motivação superior, de um dever. Descrente de que os homens abram mão de suas paixões, Tocqueville

11 Nos rascunhos d'A Democracia, lê-se: "Il y a une doctrine de l'intérêt qui consiste à croire qu'on doit faire plier l'intérêt des autres hommes devant le sein et qu'il est naturel et raisonnable de ne s'embarrasser que de celui-là. C'est un égoïsme instinctif, grossier, qui mérite à peine le nom de doctrine". (Tocqueville 2010: 924).

12 "Elle [la doctrine] est renfermée dans celle de l'utile, mais n'en fait qu'une partie" (idem).

13 Além de Jaume, Guellec também afirma a recusa de Tocqueville de se fiar a Bentham (Guellec 2004: 401). Há teses divergentes nesse aspecto da obra. Certos estudiosos salientam a proximidade de Tocqueville com Jeremy Bentham, entre outros: Pierre Birnbaum (1970) Jean-Claude Lamberti (1983).

14 "Il y a enfin une doctrine infiniment plus pure, plus élevée, plus immatérielle suivant laquelle la base des actions est le devoir" (idem).

Araucaria. Revista Iberoamericana de Filosofia, Política, Humanidades y Relaciones Internacionales, año $21, \mathrm{n}^{\circ} 42$. Segundo semestre de 2019. Pp. 449-474. ISSN 1575-6823 e-ISSN 2340-2199 doi: 10.12795/araucaria.2019.i42.19 
afirma que essa doutrina ensina o homem a morrer, visto que as recompensas do "combate aos vícios" (para empregar os termos das alegorias cristãs) encontrarse-ão em outro mundo. Trata-se de franca oposição à doutrina do interesse bem compreendido, a quarta doutrina do interesse exposta pelo autor, a qual faz o homem aprender a viver no presente, pois a realização de seus interesses está na terra, nos termos dele. À diferença entre a terceira e quarta doutrinas, central no argumento do autor, voltaremos adiante.

Ora, mostramos as evidências textuais que tornam explícita a investigação de fundamentos morais ou princípios da ação para as ações políticas democráticas. Mas qual seria o sentido de se inserir em um debate sobre doutrinas do interesse? $\mathrm{Na}$ "Advertência", Tocqueville afirma que "a democracia não pode dar os frutos que os homens esperam senão em combinação com a moralidade". Nas anotações do plano de trabalho do Tomo II d'A Democracia, ele afirma que "a doutrina do interesse bem compreendido é a doutrina filosófica que a igualdade faz nascer" (Tocqueville 2010: 759, nota a) e que "esse mesmo estado social fez com que os homens adotassem a doutrina do interesse bem compreendido como regra principal de vida" (idem). Essas duas proposições encontradas nas anotações para $A$ Democracia nos permitem afirmar que, mediante essa investigação acerca de doutrinas morais, o autor pretendia entender o fundamento moral da ação concertada dos homens, em um estado social democrático que não mais estabelecia vínculos necessários e permanentes entre as pessoas, originados do nascimento delas. Não por menos, como já afirmamos, a discussão acerca da doutrina é inserida na Parte II, no Tomo II, d'A Democracia, na qual Tocqueville visa discutir os efeitos da democracia sobre os sentimentos dos americanos, partindo da explicação das razões pelas quais os povos democráticos seriam menos zelosos na defesa da liberdade por serem compelidos, nesse estado, aos apetites do conforto material e da vida privada. Concentrados exclusivamente na segurança material e na defesa obstinada da igualdade, é a ideia de liberdade que lhes escapa, tornando-se "arrebatados pelas conquistas", mantendo-se "fora de si", "sem atentar para o domínio de si". Os termos escolhidos pelo autor para explicar tal arranjo social conotam o assentimento dos homens, em tal situação, ao domínio de outrem. A fruição material é apresentada como o prazer mais elevado no estado igualitário, razão pela qual eles não desejam senão a paz pública e a tranquilidade. Os homens das sociedades democráticas reclamam a boa ordem, mas, nesse caso, Tocqueville atesta a escravidão deles à sua paixão: "a paz pública é um grande bem; mas não quero esquecer que é através da boa ordem que todos os povos chegam à tirania" (Tocqueville 2004: 173; TII, P2, c14). Reconhecemos, pois, que contra uma consequência possível do individualismo, traço inelutável da democracia, o autor está sustentando, em tintas clássicas, que o homem deve ser senhor de si, em nome da própria liberdade: "uma nação que não requer de seu governo mais que a manutenção 
da ordem já é escrava no fundo do coração; é escrava do seu bem-estar, e o homem que a deve aguilhoar pode aparecer" (idem).

Segue-se, então, o argumento bastante conhecido de Tocqueville: além de certo arranjo institucional e das leis, profusamente discutidas no Tomo I de sua obra, a análise minuciosa nos indica que a preservação do estado democrático dependerá de alguma disposição ativa presente nos costumes dos homens, nos seus hábitos associativos, no seu envolvimento constante nos assuntos comuns, evitando a degeneração da democracia em despotismo. Desse modo, se a igualdade era o princípio do novo estado social e se tal princípio se convertia na maior paixão dos homens dessa sociedade - desejando-a até mesmo em situações nas quais a liberdade era sacrificada -, eles não seriam levados à desordem moral (e tampouco a república privava-os de seu interesse pessoal ${ }^{15}$ ), porque essa doutrina notada entre os americanos levava-os a bem compreender os seus interesses. Com efeito, ela se destacava como a "regra principal da vida", nos termos do autor, notada entre os estadunidenses, os quais são marcados pelo individualismo, tal como os demais povos democráticos.

\section{A Doutrina do Interesse Bem Compreendido}

Nesta seção nos ocupamos da quarta doutrina delineada pelo autor, cuja análise constitui os capítulos oito e nove da Parte II do Tomo II d' $A$ Democracia. Iniciamos a discussão com a exposição resumida da interpretação dos comentadores selecionados sobre essa temática tocquevilleana. Sabemos que não se trata de expor toda a interpretação deles e que recortes podem dificultar a compreensão total de obras de comentário. Entretanto, a brevidade na exposição se justifica pela necessidade de tratar do tema específico do presente artigo e tem por objetivo contrastar, em seguida, a nossa leitura com elementos destacados nessas interpretações.

Segundo o intérprete Martin Zetterbaum, a paixão material dos homens nos tempos democráticos é tida por Tocqueville como o "ponto imutável" de uma sociedade de igualdade de condições, isto é, que derrubou a importância de todas as fontes tradicionais de moralidade, que se apartou do persuasivo argumento das vantagens alcançadas no plano celestial, quando a conduta da alma fosse apropriada na terra (Tocqueville 2001: 279; TI, P2, c6). Ao assumir a centralidade dos interesses, Zetterbaum interpreta a doutrina do interesse bem compreendido (ao menos, a princípio) como a solução tocquevilleana ao "problema da democracia", qual seja, a ausência de um fundamento

${ }^{15} \mathrm{O}$ argumento irretocável nesse ponto é de Spitz ao examinar o modo pelo qual Tocqueville cinde "a alternativa simplista e primária da liberdade negativa e da liberdade positiva" (Spitz 1995: 475-490). 
moral como modelo de ação política que contorne os efeitos da instituição democrática. Com efeito, aferir o lugar que ocuparia a doutrina do interesse no argumento tocquevilleano passaria, de saída, pela compreensão de como um interesse é modificado quando "bem compreendido". Na obra Tocqueville and the problem of democracy, Zetterbaum reconhece que tantas respostas podem ser dadas quanto são distintas as teorias filosóficas que tentaram explicar a natureza humana, bem como os seus propósitos, as quais certamente não estariam fora do alcance tocquevilleano. Todavia, ele é peremptório ao afirmar que "no contexto de sua preocupação com a democracia, o interesse é compreendido principalmente em um sentido econômico" (Zetterbaum 1967: 103). O comentador sugere que, para Tocqueville, desde que considerado de uma perspectiva esclarecida, o próprio bem-estar material (one's own material welfare) daria origem ao bom ordenamento político. Eis o enfraquecimento do argumento de Tocqueville, segundo o crítico, posto que o francês apelaria para um argumento de profundo comprometimento moral e até mesmo de profunda mudança na natureza humana para sustentar um equilíbrio entre o estado social democrático e a excelência, a igualdade e a liberdade.

A concordarmos com a leitura do autor, Tocqueville teria falhado no problema posto pela democracia ${ }^{16}$, pois a oposição entre a devoção aos próprios interesses e aos interesses comuns não seria resolvida em seus escritos. Além disso, ainda segundo o comentador, Tocqueville apelaria a um argumento de tipo "mão invisível” para articular "a busca de um povo pelo seu próprio bem ao bem da humanidade como um todo" (Zetterbaum 1967: 156).

A nosso ver, trata-se de uma leitura contestável, porque o comentário da doutrina tem por pressuposto a oposição demasiado cerrada entre os interesses próprios a um homem e os comuns, amparada no endosso do sentido mais difundido da palavra "interesse", a de espera de um ganho econômico. Mais do que isso. Posto nestes termos, a resolução do problema implicado na instituição de uma sociedade democrática não passaria senão por uma mudança radical na natureza humana - a qual aludiria Tocqueville (cf. Zetterbaum 1967: 159). Essa leitura parece-nos pouco convincente, como sustentaremos na sequência do artigo.

Tomemos os comentários de outro autor, Roger Boesche, sobre a mesma tópica. Na seção “Tocqueville's Dislike of a Republic Founded on Self-interest”, no décimo capítulo de The Strange Liberalism of Tocqueville, Boesche acentua os "sacrifícios de si" feitos aos semelhantes, em nome da felicidade e interesse próprios, na leitura que apresenta da doutrina do interesse bem compreendido. Se o autor parece correto ao afirmar que os estudos mais atentos da obra tocquevilleana separam o amigo de Beaumont da defesa de uma ordem política ancorada estritamente em engrandecimento individual, o argumento parece

\footnotetext{
${ }^{16}$ Alusão ao título do capítulo de Zetterbaum (1967) “The problem of Democracy Revisited".
} 
perder precisão justamente por sugerir o afastamento de qualquer vestígio de interesse particular na compreensão de política adotada por Tocqueville. Situando o francês ao lado de Pascal, Montesquieu e Rousseau, os quais seriam defensores de certa "virtude republicana" (noção, aliás, apenas referida no texto), o autor contesta as leituras que aproximam Tocqueville dos chamados "pluralistas modernos", aos quais caberia apenas sustentar que instituições republicanas poderiam existir sem a virtude antiga, diante de um equilíbrio dos interesses: "as ações autointeressadas de grupos e indivíduos traria o bem comum pelo equilíbrio de grupos e interesses com um mínimo de intervenção do governo" (Boesche 1981: 194).

Que as passagens extraídas da obra tocquevilleana sejam perfeitamente selecionadas para corroborar o seu argumento não pode ser negado: são trechos de cartas, passagens extraídas d'A Democracia, discursos no Parlamento, além de trechos dos diários compilados em Viagens a América. O esforço de Boesche é mostrar que entre a busca do bem comum e da satisfação dos interesses privados, o parisiense buscaria extrair do exemplo da democracia americana a justificação de uma ética amparada nos deveres públicos (cf. Boesche 1981: 195). A leitura de Boesche não nos parece equivocada no que concerne às implicações morais de uma doutrina que não se ampara exclusivamente no interesse, todavia, o argumento do autor parece insuficiente por desconsiderar qualquer traço de particularidade ou de interesse que não os comuns contido na doutrina tocquevilleana, tornando-a uma espécie de continuidade da leitura dele acerca da virtude romana, o patriotismo antigo.

Como discutimos na primeira seção deste trabalho, já nos rascunhos de sua obra, tal acepção de virtude foi deliberadamente negada por Tocqueville. Isso não por se tratar de uma virtude antiga, mas por sê-lo inócuo como o fundamento moral de uma doutrina democrática e, portanto, ao alcance da generalidade de homens médios, os homens da democracia.

Sem desprezar as contribuições das interpretações de Zetterbaum e Boesche, o próximo momento do texto visa propor outra leitura da doutrina do interesse. Para tanto, iniciaremos a discussão pela compreensão da partícula adjetiva na "doutrina do interesse bem compreendido", para discutir, por fim, o que a escolha de Tocqueville por tal termo revelaria e como essa escolha permitiu ao autor distinguir essa doutrina moral de novo tipo de acepções anteriores da virtude, em diálogo com Montaigne e Rousseau.

\subsection{O que torna bem compreendido um interesse?}

Talvez pelo ofício de tradutor, um dos raros críticos a se demorar na análise do significado de "intérêt" na doutrina do interesse bem compreendido é Arthur 
Goldhammer ${ }^{17}$. O autor salienta a sutileza da palavra que, no original francês, não evoca exclusivamente a doutrina de motivação utilitária que a palavra "self-interest" poderia portar. É por isso que talvez não seja apropriado traduzir o termo para "interesse próprio" bem compreendido, pois isso equivaleria ao fechamento de um sentido eminentemente econômico ou de vantagens de ganho exclusivamente pessoais. O cuidadoso artigo do tradutor se constrói como uma tentativa de sustentar a sua hipótese de interpretação desse tema, qual seja, a de que a solução de tradução para "well understood" é equivocada, pois retira a ambiguidade que "interesse" guarda (Goldhammer 2006: 146), ao passo que a escolha "properly understood" (a opção dele, aliás) levaria o leitor a perceber a postulação de um conceito bastante escorregadiço: "o que nós consideramos ser do nosso interesse depende necessariamente de como vemos o mundo e, em particular, de onde situamos o horizonte temporal. Portanto, cabe-nos compreender o nosso interesse não apenas bem, mas propriamente" (idem). Nessa leitura, compreender "bem" um interesse é a ação na qual se perscruta em que consiste a busca de interesses e necessidades individuais, quando confrontados com os interesses comuns. Com efeito, Goldhammer ressalta justamente que o artifício dessa acomodação entre os limites das necessidades individuais e os interesses comuns é feito de modo apropriado ("properly") ou bem feito ("bien").

Dito isso, parece que estamos em condições de afirmar que não concedemos ao termo interesse o seu valor de face, imediatamente reconhecível como um proveito econômico. Além disso, negamos que o advérbio "bem" empregado à compreensão do interesse implique um conceito que traga exclusivamente vantagens, bem-estar e uma situação materialmente cômoda a um indivíduo. Lembremos que, de acordo com as notas de preparação da obra apresentadas na seção anterior, Tocqueville refuta, de saída, o egoísmo cego como elemento capaz de forjar uma doutrina moral sólida o bastante para amparar as ações dos homens nas sociedades democráticas. Não convém, portanto, sobrepor à obra tocquevilleana a fábula mandevilleana, na qual os homens são irrevogavelmente

\footnotetext{
${ }^{17}$ Exegeta, o autor apresenta o mesmo cuidado com o advérbio "bien". Ele não aborda essa questão a partir dos possíveis interlocutores de Tocqueville, mas a partir da recepção da obra, indagando a razão pela qual o termo "l'intérêt bien entendu" teria recebido traduções tão diversas. Goldhammer não adota a terminologia de Henry Reeve - tradutor inglês de Tocqueville - "self-interest rightly understood"; nem a de James Schleifer - que preparou a edição crítica d'A Democracia - "enlightened self-interest"; tampouco a versão dos straussianos Harvey Mansfield e Delba Winthrop "self-interest well understood". É relevante a reflexão que o autor tece em torno do advérbio "bien", pois, como ele esclarece, o leque semântico do morfema "bem", tão amplo quanto o "bien" francês, não se esgota inteiramente no sentido de "well". Todavia, não se trata apenas de precisão linguística, reconhecemos, mas de interpretações concorrentes acerca da temática tocquevilleana. Se é verdade que qualquer fórmula adotada na tradução manterá alguma medida de arbítrio, a escolha entre formulações tão diversas quanto as traduções anteriormente mencionadas deve, ao menos, fornecer as razões de sua pertinência. É apenas por uma questão de premissa, e não de prova, provoca Goldhammer, que os tradutores de Tocqueville assimilariam "bien" imediatamente a "well" ou "rightly".
} 
egoístas e, portanto, dos vícios privados se originariam benefícios públicos, apenas por uma consequência de amor autointeressado.

A nossa interpretação, a partir das discussões mais amplas da recepção e tradução do termo, é a de que o advérbio (na partícula adjetiva "bem compreendido") não representa senão um modo justo, uma maneira conveniente de perscrutar o que seria o interesse, sabendo que não se trata de uma justificação que o indivíduo produza a si mesmo, radicado da sociedade, mas um intento de razoabilidade atestado pela experiência que envolve o equilíbrio entre os interesses individuais e os comuns. Isso nos indica que estamos tratando de uma disposição política em uma sociedade democrática, cujos indivíduos são caracterizados pelo seu egoísmo. O modo pelo qual esse egoísmo será, então, "habilmente canalizado", para empregarmos o termo de Jaume, é o que está em questão (Jaume 2008: 47). Na medida em que a identificação do interesse não é imediata e tampouco corresponde a um mero pertencimento de classe social, mas tem por referência qualquer objeto de desejo e paixão, é compreensível a razão que leva o autor a escolher termos que façam notar que se trata de uma doutrina meditada e refletida (ou esclarecida). A leitura seria equivocada, portanto, se fosse afirmado que o interesse bem compreendido é a "teoria geral" mediante a qual os estadunidenses atingiam o seu interesse aparente ou aquilo que é de posse exclusiva e imediata de um indivíduo.

Nas considerações morais acerca da sociedade estadunidense, Tocqueville reconhece que as crenças cederam lugar ao raciocínio e os sentimentos ao cálculo ${ }^{18}$, de modo que lançados às suas paixões, os homens precisam estabelecer o campo moral associado a um ponto fixo, um dado comum entre eles: o seu interesse. O interesse é o motor do sistema ("L'intérêt, voilà le moteur de système"), na expressão empregada por Arnaud Coutant (2007: 446), para realçar que se trata de uma motivação potente o bastante, dissipadora de forças contrárias, para fundamentar moralmente as relações entre os homens ou cimentar o pacto possível em uma sociedade democrática, sem a qual a liberdade estaria em desequilíbrio. Desse modo, Tocqueville apresenta um meio de contornar os males da democracia, sem o qual ela se converteria em um estado social esgarçado pela inveja e pelo ódio, sentimentos nela originados. Não é por outra razão que Meuwly apresenta a doutrina do interesse bem compreendido como um "fator de equilíbrio social" (Meuwly 2002: 208-9).

Ora, sendo a igualdade de condições o princípio fundamental do estado social democrático, Tocqueville não se demora em premissas antropológicas das suas análises, porque lhe importa menos perscrutar se o interesse de cada um seria "naturalmente bom" do que o ato implicado na realização dos interesses particulares no que diz respeito à sua relação com os interesses comuns. Com

${ }^{18}$ Cálculo e raciocínio são, portanto, elementos que caracterizam a doutrina. A linguagem é utilitária, ainda que, como argumentamos na seção 1, a doutrina não deva ser subsumida ao utilitarismo. 
efeito, é como se Tocqueville retomasse as indagações de Rousseau, n'O Contrato Social, e investigasse como os homens da sociedade estadunidense paradoxalmente se entregam à associação e, ao mesmo tempo, permanecem tão livres quanto os demais em relação a tal força comum; como tais homens ultrapassam aquilo que seria algo como a mera soma dos egoísmos individuais, sem perder de referência os próprios interesses. E o problema fundamental da associação - para o qual o Contrato prometia ser uma resposta - não era justamente encontrar uma forma de associação que, parafraseando Rousseau (no capítulo VI, do Livro I), defende e protege de toda força comum a pessoa e os bens de cada associado ${ }^{19}$ ? Com efeito, a inquietação de Tocqueville, embora tenha sob os olhos outra sociedade, é muito semelhante à sentença do genebrino na qual se assevera que os homens deveriam aprender a preferir o interesse bem compreendido a seu "interesse aparente" (cf. Rousseau 2012: 40-1). A interrogativa retórica do excerto, porém, serve a Tocqueville como reforço do contraste com as sociedades aristocráticas, após a constatação acerca da centralidade do interesse, como fagulha nas ações humanas, no interior das sociedades democráticas:

Deve-se contar, portanto, com que o interesse individual se torne, mais que nunca, o principal, se não o único, móvel das ações dos homens; mas resta saber como cada homem entenderá o seu interesse individual [...] Cumpre pois esclarecê-los a qualquer preço, porque a época das devoções cegas e das virtudes instintivas já vai longe de nós (Tocqueville 2004: 150; TII, P2, c8 grifos nossos).

A aproximação com as considerações de Rousseau, bem como o seu limite, parece estar neste excerto. Não temos o objetivo de esgotar neste artigo as semelhanças entre os autores, mas cumpre indicar algumas proximidades que fornecem indícios de que o genebrino poderia ser um interlocutor post-mortem de Tocqueville nas considerações acerca da virtude ${ }^{20}$. As argumentações são formalmente semelhantes, pois Rousseau também parte de um retrato geral da sociedade para chegar a esse homem que no "silêncio das suas paixões" apresenta um ato de entendimento mediante o qual lhe é fornecido um direcionamento (que, sabemos, é a vontade geral) para a realização dos seus propósitos. Rousseau não nos deixar esquecer da falácia que seria atribuir ao

${ }^{19}$ Referência ao seguinte excerto: "encontrar uma forma de associação que defenda e proteja com toda a força comum a pessoa e os bens de cada associado, e pela qual cada um, unindo-se a todos, só obedeça, contudo a si mesmo e permaneça tão livre quanto antes" (O Contrato social, LI, cap.6; Rousseau 2006: 20).

20 Estamos de acordo com Jean-Louis Benoît, a quem as relações que Tocqueville estabeleceu com a obra de Rousseau são diferentes no volume I e II da obra - o que não é o caso, por exemplo, do diálogo mais uniforme com Montesquieu. Benoît corrobora a nossa hipótese: "Alexis pose le problème fondamental de la démocratie et engage avec Jean Jacques un débat post-mortem qui se poursuivra cinq ans plus tard" (Benoît 2013: 224-225).

Araucaria. Revista Iberoamericana de Filosofía, Política, Humanidades y Relaciones Internacionales, año $21, \mathrm{n}^{\circ} 42$. Segundo semestre de 2019. Pp. 449-474. ISSN 1575-6823 e-ISSN 2340-2199 doi: 10.12795/araucaria.2019.i42.19 
homem social as características que cabem ao homem isolado, bem como da necessidade que os homens possuem de seus semelhantes para a realização dos diversos interesses, tão logo estejam satisfeitas as mais elementares necessidades humanas: "as nossas necessidades nos reúnem a medida que as nossas paixões nos dividem, e quanto mais nos tornamos inimigos dos nossos semelhantes menos podemos passar sem eles" (Rousseau 2012: 34).

Diante do imperativo da concorrência dos interesses, o estado de independência humana revela-se como um paradoxo suportado pelos homens: sentem-se independentes, mas, tão logo as primeiras necessidades surgem, precisam necessariamente uns dos outros; essa dependência para a realização das mais fundamentais necessidades não pode levar à submissão de uns pelos outros. Com efeito, projeta-se a sombra da desconfiança sobre cada um dos homens, tão inseguro quanto os seus semelhantes de que a sua moderação voluntária possa garantir a estabilidade dessa sociedade. Considerando inexistentes a devoção desinteressada ao bem comum e a disposição voluntária individual, o autor indaga que considerações poderiam ser antepostas a essa impotência que se projeta sobre os homens, lançando-os a um caudal de desconfiança mútua, se a religião não vem ao socorro da moral (cf. Rousseau 2012: 37)? Mesmo diante de tal quadro que deflagra a ausência de um fundamento da autoridade moral, Rousseau refuta a postulação de certo egoísmo instintivo presidindo o estado natural e generalizável à espécie. Segundo Rousseau, o erro de Hobbes teria sido "ter suposto este estado à espécie e tê-lo tomado como causa dos vícios, dos quais ele era o efeito". Caracterização da espécie humana considerada como depravada e vulgar na pena de Tocqueville, ainda que ele não cite diretamente Hobbes ao esboçar a doutrina do interesse com feições completamente egoístas.

É certo que o autor genebrino alude a alguma solução no próprio seio da sociedade que fez nascer tais males. Tal como o veneno comporta no seu campo de aflição o antídoto, ele afirma: "longe de pensar que não haja nem virtude e nem felicidade para nós e que o céu nos tenha abandonado sem recursos à depravação da espécie, esforcemo-nos de extrair do próprio mal o remédio que deve curá-1o" (Rousseau 2012: 40). Para o autor, em outros tempos, o amor à pátria garantiria a adequação da vontade individual à geral:

os maiores prodígios da virtude foram produzidos pelo amor à pátria: este sentimento doce e vivo, que une a força do amor próprio [l'amour propre] a toda a beleza da virtude, lhe dá uma energia que, sem desfigurá-la, torna-a a mais heroica de todas as paixões (Rousseau 2006b: 99).

Nesse ponto, insistindo em que a virtude estaria na adequação da vontade particular à geral ["Queremos que os povos sejam virtuosos? Comecemos, então, fazendo-os amar a pátria”], Rousseau lança mão de um elemento exterior, 
por assim dizer, à vontade dos homens: "[...] que a humanidade concentrada entre os cidadãos adquira entre eles uma nova força pelo hábito de ser e pelo interesse comum que os reúne" $(\text { idem })^{21}$. Mas Tocqueville é o autor que resiste à ideologia francesa da vontade geral (Guellec 2004: 401). Diante de tal constatação, não seria equivocado afirmar que, se é verdade que os autores palmilham o mesmo terreno no que diz respeito ao desencanto da virtude própria das sociedades modernas, a solução política para a ação comum não é a mesma. Na pena tocquevilleana dificilmente vislumbraríamos qualquer alusão a um sentimento natural de humanidade ao qual Rousseau parece recorrer - ao menos no artigo "Economia" para a Encyclopèdie -, pois a doutrina não se fixa nos hábitos e costumes dos estadunidenses por algum elemento inerente à natureza humana, mas por uma contingência histórica.

Mas se o caminho da argumentação para se chegar aos costumes não foi o mesmo, Tocqueville certamente conhece e alude à obra do genebrino, quando afirma que as devoções e as virtudes instintivas, traços característicos das sociedades aristocráticas, já estavam longe dos homens nas sociedades democráticas. Com esse paralelismo, recurso habitual que afasta intencionalmente do campo imediato das considerações as formas sociais antigas para melhor realçar a experiência democrática, Tocqueville lança luz sobre a passagem de uma sociedade aristocrática, amparada na devoção e no esquecimento de si, para uma sociedade cuja virtude mostrava-se útil (l'utilitarisme éclairé) à conquista do interesse particular. Era disso, afinal, de que se tratava o II volume d'A Democracia na América: o estado social democrático fez nascer diversos sentimentos e opiniões que não existiam nas velhas sociedades aristocráticas da Europa. Portanto, se Tocqueville parte da mesma constatação acerca da centralidade dos interesses no estado moderno, as implicações morais parecem bastante distintas das reflexões de Rousseau. Com essas considerações, estamos afirmando que, embora a temática tenha sua origem num diálogo post-mortem com o genebrino, é possível notar no desenvolvimento da temática a inclinação à prosa de Montaigne. Seguimos com mais vagar a nossa argumentação nesse momento.

Ao apresentar o lugar ocupado pela doutrina do interesse, a partir da passagem das sociedades aristocráticas para as democráticas e, portanto, dos novos elementos capazes de servirem de estímulo para a virtude (não mais a glória, e sim os interesses), Tocqueville afirma: "não há poder na terra capaz de impedir que a igualdade crescente das condições leve o espírito humano à busca do útil e disponha cada cidadão a se fechar em si mesmo" (Tocqueville 2004:

21 Não sustentamos aqui uma ideia simplista de Rousseau mediante a qual apenas restaria aos homens o sacrifício em nome do grupo, tampouco a de que a obrigação do governo seria a de impor ao povo a vontade geral, anulando as particularidades. O problema aqui, em termos gerais, é que no artigo da Enciclopédia Rousseau supõe uma virtude como "conformidade em tudo" à vontade geral mediante educação pública (cf. Lepan 2002: 151). 
150). Tal adágio faz eco à sentença de Montaigne, nos Ensaios, na qual ele assinala os excessos da presunção humana, reconhece a grandeza que apenas caberia a Deus, e se volta a essa natureza humana mortal e fraca cujos ideais devem ser mais baixos, desde o exórdio do Da Glória:

Eis como apenas a Deus cabem glória e honras e não há nada tão distante da razão quanto nos pormos a buscá-las para nós mesmos; pois, sendo interiormente pobres, nossa essência sendo imperfeita e precisando continuamente de melhora, é nisso que devemos nos afainar (Montaigne II, 16: 429 grifos nossos).

Reservamos, por assim dizer, a glória a Deus e buscamos nós, providos de uma condição imperfeita, aquilo de que temos maior necessidade; nos ocupamos do necessário e, apenas em segundo plano, dos ornamentos trazidos pela virtude. A disjunção entre glória e virtude efetuada por Montaigne é passo fundamental - sem com isso querermos estabelecer nenhuma continuidade entre as obras - para a junção que Tocqueville opera entre virtude e interesse, com raciocínio (irônico) análogo ao autor dos Ensaios: “duvido que os homens fossem mais virtuosos nas eras aristocráticas do que nas outras, mas é certo que nelas se falava sem cessar das belezas da virtude, mas estudavam em segredo de que modo ela era útil" (Tocqueville 2004: 147, grifos nossos). A virtude sublime - característica da sociedade de homens voluntariamente devotados ao bem comum - ganha o segundo plano das considerações tocquevilleanas e, ao modo do seu antecessor, Montaigne, a natureza humana fragmentada, interessada antes pelo útil do que pelo belo, ganha centralidade. Era esse o "contrato social" possível na democracia: "Nos Estados Unidos, quase não se diz que a virtude é bela. Sustenta-se que é útil, e prova-se isso todos os dias. Os moralistas americanos não pretendem que seja necessário sacrificar-se a seus semelhantes, porque é grandioso fazê-lo". E completa adiante: "Perceberam que, em seu país e em seu tempo, o homem era voltado para si por uma força irresistível e, perdendo a esperança de detê-lo, passaram a pensar apenas em conduzi-lo" (Tocqueville 2004: 148).

É justamente nesse momento da argumentação e diante da dificuldade de explicar as razões pelas quais os moralistas teriam convencido os seus cidadãos da pertinência e utilidade de agir de certo modo que Tocqueville lança o argumento de autoridade (e não estaria pensando na audiência francesa?), citando Montaigne: "Se, por sua retidão, eu não seguisse o caminho reto, seguilo-ia por ter descoberto por experiência, que no final das contas é comumente o mais feliz e o mais útil” (idem).

Mas é também um apelo irônico a Montaigne, seguindo Laurence Guellec, invocado na argumentação como autoridade ou referência cultural dos americanos: "A doutrina não é nova, portanto; mas, entre os americanos 
dos nossos dias, ela foi universalmente admitida, tornou-se popular" (idem $)^{22}$. Antes disso, o autor reservara os primeiros parágrafos do oitavo capítulo para contrastar as sociedades aristocrática e democrática, do ponto de vista dos deveres. Na primeira, a doutrina oficial em matéria de moral indicava a conveniência de fazer o bem sem interesse. Com isso, professavam que uma ação deveria ser interessada apenas na beleza inerente a certo ato tido por virtuoso. O fato é que "à medida que a imaginação voa mais alto e que cada um se concentra em si mesmo" - essa é a formulação que marca a passagem temporal no nascimento de uma nova moral no estado social de igualdade "[...] os moralistas se assustam com a ideia de sacrifício e não ousam mais oferecê-lo ao espírito humano" (Tocqueville 2004: 149). Por seu alto rigor no esquecimento de si, "como Deus mesmo", ironiza o autor, essa moral elevada não é praticável senão quando o mundo era conduzido por um pequeno número de homens. Num mundo democrático, os homens amparam-se não na beleza das ações, mas nas vantagens individuais dos cidadãos nos pontos de coincidência com o interesse geral $^{23}$. $\mathrm{O}$ que equivale a afirmar que a utilidade se vincula, nessa moral de novo tipo (já propagada por Montaigne, mas registrada no Novo Mundo), à justiça, porque são atos não mais ao alcance de poucos venturosos, mas de todos.

Deve-se notar que a investigação desse apelo ressalta a distância temporal ("porque a época das devoções cegas [...] já vai longe de nós") na qual parece residir a diferença de compreensão dos interesses entre dois mundos, o aristocrático e o democrático ${ }^{24}$. Outrora estabelecidos em suas crenças, em uma ordem cuja legitimidade não era contestada ["houve um tempo, sob a antiga monarquia, em que os franceses experimentavam uma espécie de alegria ao se sentirem entregues, sem recursos, ao arbítrio do monarca [...]" (Tocqueville 2001: 274)], os homens se atavam a um amor instintivo à pátria. Mas há uma ruptura nessa ordem e nisso reside o interesse da reflexão moral tocquevilleana e, especificamente, da virtude em sociedades democráticas. Em tal ruptura, os costumes são mudados, as crenças são abaladas, o orgulho das lembranças é esmaecido, como as seguintes linhas permitem notar:

22 Empregamos “ironia” no sentido exposto por Laurence Guellec: “L’ironie n’est plus polémique et encore moins pamphlétaire puisque Tocqueville ne se bat pas au nom d'un monde condamné à disparaître mais entérine à l'inverse la disparition du modèle culturel aristocratique. [...] L'ironie satirique est l'exacte mesure de la distance ou du recul que Tocqueville inscrit entre lui-même et la société qu'il décrit" (Guellec 2004: 402).

${ }^{23}$ Haveria outra via para explicar esse ponto de convergência que, entretanto, não contradiz o argumento sustentado neste artigo: trata-se da filiação de Tocqueville aos moralistas franceses do século XVII, entre os quais, La Rochefoucauld, Pascal, além dos Jansenistas. Para eles, a teoria do amor próprio não separa os homens uns dos outros, mas leva-os a agir em concerto e a se servirem mutuamente em nome do julgamento que os outros podem ter de si mesmos. Essa via de raciocínio seria o "interesse propriamente compreendido" cf. Jaume 2008: 159-193.

${ }^{24}$ Referência ao título de Sheldon Wolin (2001), Tocqueville between two worlds. 
Então, os homens não percebem mais a pátria, a não ser sob uma forma fraca e duvidosa; não a colocam mais nem no solo, que se tornou, a seus olhos, uma terra inanimada, nem nos usos de seus ancestrais, que foram ensinados a considerar um jugo; nem na religião [...]; nem nas leis [...]; nem no legislador [...] (Tocqueville 2001: 275; TI, P2, c6).

Se o autor afirma que o amor pela cidade (para empregarmos a imagem de Rousseau) fora banido, restaria ao homem, entregue a si mesmo, interpretar o interesse pessoal. Como interpretá-lo é a questão que o parisiense leitor de Rousseau não deixa de buscar ${ }^{25}$ : onde repousaria na sociedade de igualdade de condições, na qual os espíritos se assemelham, as crenças se esmaecem e as vontades se equivalem, o fundamento que associaria a vida particular e o bemestar de seus concidadãos? É então que o autor expõe mais sistematicamente, a partir do quarto parágrafo, a teoria geral "com a ajuda da qual [os estadunidenses] alcançam esse resultado”, essa nova espécie de virtude.

A dificuldade, alguém poderia objetar, é a de saber a que se refere o sacrifício e se, como espartanos, os homens nas sociedades de igualdade sacrificariam os seus próprios desejos a um bem julgado maior, amparados em uma ideia de dever.

O exame mais detido da argumentação tocquevilleana no capítulo nono, "Como os americanos empregam a doutrina do interesse bem compreendido em matéria de religião", permite-nos sustentar que, embora o autor empregue no tratamento da questão o termo "sacrifício", ele não o faz ao modo de certos moralistas para os quais a felicidade na vida estaria na vigília cerrada das paixões ou, para empregar os termos do autor, "que só seria possível adquirir uma felicidade duradoura recusando-se mil prazeres passageiros e que, enfim, é preciso triunfar sem cessar sobre si mesmo para melhor servir" (Tocqueville 2004: 151; TII, P2, c9). Com efeito, não é preciso vencer os próprios impulsos, refreando-os, e tampouco adotar "princípios puros" como guias das ações humanas, pois o homem pressuposto por Tocqueville é um sujeito mergulhado nos seus interesses e desejoso, e não um ser de natureza elevadíssima: "Um americano se ocupa de seus interesses privados como se estivesse sozinho no mundo e, no instante seguinte dedica-se à coisa pública como se os estivesse esquecido" (Tocqueville 2004: 174; TII, P3, c14). O interesse é um dado, mas conexo à virtude.

Em uma de suas anotações, Tocqueville afirma que a doutrina do interesse bem compreendido pode ser útil em todas as sociedades, mas "muito mais útil" naquelas em que os homens não se retiram para o prazer platônico de fazer o

\footnotetext{
${ }^{25}$ Nesse aspecto, discordamos de Zetterbaum, ao afirmar que Tocqueville teria passado longe dessa discussão: "It is disconcerting to realize that Tocqueville seems oblivious to the possibility of some irreconcilable conflict between public and private interest. He does not even consider whether men are well equipped to deal with the common good as they are with their own..." (Zetterbaum 1967: 148).
} 
bem e nas quais eles veem o outro mundo pronto para deles escapar. Isto é, convencer os homens mediante recompensas futuras seria tarefa inútil. Aliás, a religião é útil, para Tocqueville, no capítulo mencionado, menos porque determina princípios, mas por ensinar aos homens a fazer pequenos sacrifícios em nome de um bem maior estimado. Se as recompensas de uma tal estrutura de ação são atingidas no presente e não lançados a algum ponto distante do futuro, a virtude, pode-se dizer, ganha cada vez mais contornos temporais. E, de acordo com Pocock, o tempo é governado por forças como os costumes e a prática (cf. Pocock 1975). Com isso, nota-se que a doutrina do interesse bem compreendido, essa nova espécie de virtude, não é um constrangimento exterior à natureza dos homens, mas justamente ampara-se nas suas paixões, nos seus interesses e nos seus costumes.

Não é por menos que uma das palavras usadas com mais frequência $\mathrm{n}^{\prime} A$ Democracia é "instinto". Instinto não significa, na obra, um comportamento bruto, mas uma "espontaneidade cultivada" pelo costume - a expressão, de paroxismo ao gosto tocquevilleano, é de Goldhammer (Goldhammer 2006: 152). Se as circunstâncias observadas por Tocqueville eram inauditas, isto é, se o novo estado social oferecia a possibilidade de cada um satisfazer a sua paixão, em especial a material, não seria preciso supor que os interesses individuais fossem apagados ou que os homens não se orientassem individualmente, pois o modo pelo qual cada homem compreenderá o seu interesse individual estará sujeito ao costume ${ }^{26}$. Tal como Montaigne, o autor parece convencido de que se não são seguidos os caminhos certos, porque são certos, deve-se seguir aqueles que, no final das contas, constatou-se experimentalmente, parafraseando o autor, que no geral são os de maior utilidade.

E não haviam sido observados pelo autor os trabalhos dos legisladores que concederam vida a cada porção do território, descentralizando o poder; a administração dos pequenos negócios e as associações de mil matérias; a criação dos jornais e de eventos que reuniam os homens, a despeito da teimosa tendência à reclusão, inveja e orgulho, as paixões despertas nos tempos democráticas? ${ }^{27}$ Com efeito, ao afirmar que para alcançar a felicidade neste mundo um homem tenha "se acostumado a sacrificar sem esforço o prazer do momento ao interesse permanente" (Tocqueville 2004: 152; TII, P2, c9); Tocqueville visa realçar que tal homem não "contabiliza" os custos de agir desse modo, pois "o costume preparou-o de antemão para suportá-lo" (idem, grifos nossos).

\footnotetext{
${ }^{26}$ Qual a noção Tocqueville sustenta, quando emprega o termo "costume"? Nas palavras dele: "lembro aqui ao leitor o sentido geral em que emprego a palavra costume. Entendo por essa palavra o conjunto das disposições intelectuais e morais que os homens trazem consigo, no estado de sociedade" (Tocqueville 2001: 541, nota 8; TI, P2, c9). Há outra passagem, n’A Democracia, na qual o autor define costumes associando o termo a "mores" (cf. Tocqueville 2001: 338; TI, P2, c9).

27 Ver: "Conversations with Mr.Gray", de 22 de setembro 1831. Journey to America.
} 


\section{Considerações finais}

Como argumentamos no presente trabalho, o autor d'A Democracia não buscou fundamentar nenhuma premissa antropológica da doutrina do interesse bem compreendido, teoria social própria à democracia. Em vez disso, observando os costumes presentes na Nova Inglaterra, afirma que aos homens não deixaria de parecer sensato, razoável e justo (portanto, de acordo com o seu próprio bem) agir de tal modo. Tampouco o autor aludiu a alguma facilidade da tarefa de pensar o bem comum associado ao interesse. Pelo contrário, ao tratar do modo pelo qual os homens combatem o individualismo mediante as associações, as leis e mantêm esse gosto pela liberdade, o autor emprega termos que denotam a dificuldade de fazer os homens desviarem a visão de si mesmos.

Parece-nos coerente, portanto, a interpretação de que Tocqueville tentava depreender de uma experiência histórica específica os elementos desejáveis aos estados sociais democráticos no geral. A sociedade estadunidense fornecialhe, portanto, um modelo epistemológico (cf. Benoît 2013: 336). Para tanto, Tocqueville imprime um caráter retórico na sua prosa, visando admirar e mover ${ }^{28}$ a sua audiência. Disso não deixa dúvidas a proposição, em forma de síntese, que incitaria à ação os seus ouvintes: "os americanos combateram pela liberdade o individualismo que a igualdade fazia nascer, e venceram" (Tocqueville 2004: 150; TII, P2, c8 grifos nossos). O teor elogioso das descrições dos costumes estadunidenses, constituídas de frases hiperbólicas e carregadas de adjetivos, foi a escolha argumentativa de Tocqueville: uma escrita tão mais pungente quanto mais pretendia instruir o comportamento dos franceses, a quem se destinava a obra. Ou, para empregarmos os termos de Schleifer, o que foi dito sobre a América seria "em ampla medida, uma resposta a sua audiência francesa”. É por essa razão que Tocqueville não empreendera uma descrição positivista da democracia estadunidense, como foi amplamente lido, mas amparou a sua escrita em expedientes de persuasão ${ }^{29}$ a fim de legitimar o estado social de igualdade de condições na França ${ }^{30}$. Essa interpretação é, de resto, inteiramente coerente com a declaração tocquevilleana, na "Advertência": "enquanto eu tinha os meus olhos fixos na América, eu pensava na Europa" (Tocqueville 2010: 28, nota o). Por essa razão, o autor se dirige diretamente

\footnotetext{
${ }^{28}$ A referência incontornável neste ponto é à Retórica, de Aristóteles, LI, c2, §1.

${ }^{29}$ Sobre esse aspecto, endossamos a tese de Laurence Guellec (2004), a quem o uso pródigo de recursos expressivos e estilísticos, o apelo constante do leitor, permite notar Tocqueville em processo retórico e dirigindo-se a audiência ampla.

${ }^{30}$ Que Tocqueville tenha empreendido um esforço de categorização bem como de convencimento é interpretação comum a Guellec (2004), Lefort (1999), Mélonio (1993) e Rosanvallon (2000). Diante de homens ou inteiramente devotados à causa republicana, ou a remanescentes do jacobinismo, bem como a ultramonarquistas, que pareciam querer refazer o casamento do trono com o altar, Tocqueville não se identificava completamente com nenhum deles e era a eles que se dirigia (sua "literatura política", como ele afirma em uma carta enviada a Kergolay, em 15 dezembro de 1850).
} 
aos seus conterrâneos e, após anunciar a dificuldade do seu tema, que poderia levá-lo a suspender o juízo acerca do que acabara de descrever, segue até o final do capítulo, parágrafo a parágrafo, com exortações à doutrina do interesse bem compreendido, como "[...] de todas as teorias filosóficas a mais apropriada às necessidades dos homens do nosso tempo" (Tocqueville 2004: 149).

Com efeito, o argumento não assinala nenhuma ilusão acerca da influência que apenas as associações observadas em sua travessia do Atlântico teriam sobre a república francesa, mesmo porque em nenhum momento ele prediz tais instituições como remédio exclusivo para os males trazidos pela igualdade de condições em quaisquer sociedades. Pelo contrário. O francês reconhece que, diferente da sociedade dos salões, nas quais os poucos poderosos, reunidos e conhecidos por todos, influenciam direta e decididamente o curso da sociedade, as associações precisam comportar um grande número de cidadãos para que tenham força expressiva. Se Tocqueville enxerga nas associações o correspondente à ação dos "particulares poderosos" (Tocqueville 2004: 135; TII, P2, c5) é porque, mediante elas, os homens independentes, isolados e fracos, tal como a igualdade os fizera, poderiam adquirir a capacidade e o costume de produzir coisas em comum e por si mesmos, mantendo-se independentes - reestabelecendo a necessária relação entre a igualdade e a liberdade. Isso nos permite afirmar que ele enraíza historicamente as suas análises e se dirige a sociedades democráticas, cujo fundamento de ação, o irredutível da moral, é que mudou: a partir de então, não seria mais possível postular a virtude senão associada ao interesse. Há, portanto, uma espécie nova de virtude ${ }^{31}$, menos generosa, mas acessível a todos; não mais amparada no amor desinteressado, certamente, mas nascida das luzes, o que acaba por confundi-la com o interesse pessoal.

A doutrina do interesse bem compreendido cede aos homens a percepção que há dependência entre eles. Ela não produzia grandes devoções, mas indicava aos homens "pequenos sacrifícios", tanto "a quem os impõe a si quanto a quem deles se aproveita” (Tocqueville 2004: 148; TII, P2, c8). Tais sacrifícios, por sua vez, não produziam heroísmos, não elevavam alguns poucos homens acima do nível da humanidade, mas toda a espécie (Tocqueville 2004: 149). A doutrina do interesse evidenciava que eram raras as virtudes extraordinárias, é verdade, mas que a virtude se estendia à totalidade dos cidadãos, regularmente temperados e senhores de si. A doutrina do interesse bem compreendido é generalizável como a teoria filosófica democrática por excelência, concluímos, porque, absortos na multidão, é uma atuação virtuosa do homem a despeito de si mesmo:

31 A alusão é feita ao termo de Spitz "vertu d'espèce nouvelle” (Spitz 1995: 455) que, deve ser ressaltada, não é nova, nos termos tocquevilleanos, porque ele a atribui à Montaigne, como discutimos anteriormente. 
Várias das paixões que gelam os corações e os dividem são obrigadas então a se retirar para o fundo da alma e aí se esconder. O orgulho se dissimula; o desprezo não ousa manifestar-se. O egoísmo tem medo de si mesmo. (Tocqueville 2004: 126; TII, P2, c4). 


\section{Bibliografia:}

Armitage, David; Fitzmaurice, Andrew; Condren, Conal (eds.). Shakespeare and Early Modern Political Thought. New York, Cambridge University Press, 2009.

Benoît, Jean-Louis. Tocqueville. Paris, Tempus Perrin (2 ed.), 2013.

Birnbaum, Pierre. Sociologie de Tocqueville. Paris, 1970.

Boesche, Roger. The Strange Liberalism of Alexis de Tocqueville. New York, Cornell University Press, 1987.

Coutant, Arnaud. Une critique républicaine de la démocratie libérale. Paris, Mare et Martin, 2007.

Drescher, Seymour. Tocqueville and England. Cambridge, Mass., Harvard University Press, 1964.

Goldhammer, Arthur. Translating Tocqueville: The Constraints of Classicism.

IN: The Cambridge Companion to Tocqueville (Ed. Welch, Cheryl). New York, Cambridge University Press, 2006.

Guellec, Laurence. Tocqueville et les langages de la démocratie. Paris, Honoré Champion, 2004.

Jasmin, Marcelo. Alexis de Tocqueville: a historiografia como ciência da politica. Belo Horizonte, Editora UFMG, IUPERJ, 2005.

. Interesse bem compreendido e virtude em A Democracia na América.

IN: Pensar a República. Belo Horizonte, Editora UFMG, 2000.

Jaume, Lucien. Tocqueville: les sources aristocratiques de la liberté. Paris, Fayard, 2008.

. L'Individu effacé ou la paradoxe du libéralisme français. Paris, Fayard, 1997.

Lamberti, Jean-Claude. Tocqueville et les deux démocraties. Paris, 1983.

Lefort, Claude. Desafio da escrita política (trad. Eliana Souza). São Paulo: Discurso editorial, 1999.

Lepan, G. Les conditions de la vertu: le patriotisme. In: Rousseau. Discours sur l'économie politique (ed. Bernardi, Bruno). Paris, Vrin, 2002.

Manent, Pierre. Tocqueville et la nature de la démocratie. Gallimard, 1993.

Mansfield, Harvey; Winthrop, Delba. Tocqueville's New Political Science.

IN: The Cambridge Companion to Tocqueville (ed. Welch, Cheryl). New York, Cambridge University Press, 2006.

Mélonio, Françoise. Tocqueville et les Français. Paris, Aubier, 1993.

Meuwly, Olivier. Liberté et société: Constant et Tocqueville face aux limites du libéralisme moderne. Genève; Paris: Droz, 2002.

Montaigne, Michel de. Les Essais. II, c.16. Paris, M. Sonnius, 1595 [BnF, disponível em: <catalogue.bnf.fr/ark:/12148/cb30967155d.public>].

Montesquieu. Charles de. O espírito das Leis. (Trad. Cristina Murachco). São Paulo, Martins Fontes, 2005. 
Nicolete, Roberta Soromenho. Quando a política caminha na escuridão Interesse e virtude n'A Democracia na América de Tocqueville. São Paulo, Alameda, 2018.

Pocock, John. The Machiavellian Moment - Florentine Political Thought and the Atlantic Republican Tradition. New Jersey, Princeton University, 1975. Reis, Helena Esser. A virtude na filosofia política de Tocqueville, Philósophos - Revista de Filosofia 4 (2): 83-94 (1999).

Rosanvallon. Pierre. Le moment Guizot. Paris, Gallimard, 1985. . La démocratie inachevée. Paris, Gallimard, 2000.

Rousseau, Jean-Jacques. Du Contrat Social ou Essai sur la Forme de la République (Manuscrit de Genève). (ed. Bachofen, Blaise et al.). Paris, Librairie Philosophique J. Vrin, 2012.

- O Contrato Social - princípios do direito político (Trad. Antônio de Paula Danesi). São Paulo, Martins Fontes, 2006.

- Verbetes políticos da Enciclopédia/ Economia (Trad. Maria das Graças). São Paulo, Editora Unesp/ Discurso Editorial, 2006 b.

Schleifer. James. The Chicago companion to Tocqueville's Democracy in America, 2012.

. Making of Tocqueville's Democracy in America. LibertyFund, 2000.

Smith. Adam. The Theory of Moral Sentiments (ed. Knud Haakonssen). Cambridge, Cambridge University Press, 2002.

Wealth of Nations (ed. Jerry Evensky). Cambridge, Cambridge University Press, 2015.

Spitz, Jean-Fabien. La liberté Politique. Essai de généalogie conceptuelle.

Paris, Presses Universitaires de France/PUF, 1995.

Tocqueville, Alexis de. Selected Letters on political and society. (Ed. e trad. Boesche, Roger). Berkeley, University of California Press, 1985.

A Democracia na América: Leis e costumes (TI). (Trad. Eduardo Brandão). São Paulo, Martins Fontes, 2001.

. A Democracia na América: Sentimentos e opiniões (TII). (Trad. Eduardo Brandão). São Paulo, Martins Fontes, 2004.

. Democracy in America: Historical-Critical Edition of De la démocratie en Amérique. A Bilingual French-English edition (ed. Nolla, Eduardo). Indianapolis, Liberty Fund, 2010.

. Journey to America (ed. Mayer, J.P.), Doubleday Anchor Books, 1971.

Wolin, Sheldon. Tocqueville between two worlds - The Making of a Political and Theoretical Life. Princeton University Press, 2001.

Zetterbaum, Marvin. Tocqueville and The Problem of Democracy. Palo Alto, California, Stanford University Press, 1967. 
